\title{
Anatomy and Histochemistry of Roots and Shoots in Wild Rice (Zizania latifolia Griseb.)
}

\author{
Chaodong Yang, ${ }^{1}$ Xia Zhang, ${ }^{1}$ Junkai Li, ${ }^{1}$ Manzhu Bao, ${ }^{2}$ \\ Dejiang Ni, ${ }^{2}$ and James L. Seago Jr. ${ }^{3}$ \\ ${ }^{1}$ Engineering Research Center of Wetland Agriculture in Central Yangtze, Ministry of Education, \\ Yangtze University, Jingzhou, Hubei 434025, China \\ ${ }^{2}$ College of Horticulture and Forestry Sciences, Huazhong Agricultural University, Wuhan 430070, China \\ ${ }^{3}$ Department of Biological Sciences, SUNY, Oswego, NY 13126, USA
}

Correspondence should be addressed to James L. Seago Jr.; jseago@twcny.rr.com

Received 9 September 2013; Accepted 26 December 2013; Published 6 February 2014

Academic Editor: Muhammad Y. Ashraf

Copyright (C) 2014 Chaodong Yang et al. This is an open access article distributed under the Creative Commons Attribution License, which permits unrestricted use, distribution, and reproduction in any medium, provided the original work is properly cited.

Wild rice (Zizania latifolia Griseb.) is a famous, perennial, emergent vegetable in China. The current work explores the anatomy and histochemistry of roots, stems, and leaves and the permeability of apoplastic barriers of wild rice. The adventitious roots in wild rice have suberized and lignified endodermis and adjacent, thick-walled cortical layers and suberized and lignified hypodermis, composed of a uniseriate sclerenchyma layer (SC) underlying uniseriate exodermis; they also have lysigenous aerenchyma. Stems have a thickened epidermal cuticle, a narrow peripheral mechanical ring (PMR), an outer ring of vascular bundles, and an inner ring of vascular bundles embedded in a multiseriate sclerenchyma ring (SCR). There is evidence of suberin in stem SCR and PMR sclerenchyma cells. Sheathing leaves are characterized by thick cuticles and fibrous bundle sheath extensions. Air spaces in stems and leaves consist of mostly lysigenous aerenchyma and pith cavities in stems. Apoplastic barriers are found in roots and stems.

\section{Introduction}

Asian wild rice or water bamboo, Zizania latifolia Griseb, a member of the same grass tribe, subfamily, and family (Oryzeae, Ehrhartoideae, and Poaceae) as rice, Oryza sativa [1], is an important, aquatic plant in which young culms and rhizomes are edible, and grains, like the North American species, Z. aquatica [2], are used for food in China. The perennial stems are comprised of rhizomes with scale leaves, stolons, and culms with relatively broad leaves.

There have been relatively few studies on the submerged parts of wild rice which are adapted to wetland environments. An early study on the roots of a North American wild rice, Zizania aquatica [3], has been followed by relatively little on anatomy of the roots and stems, including Zizania latifolia [4-9], although considerable leaf anatomy is known [5]. On the other hand, the rice plant of the subfamily Ehrhartoideae has been studied much (e.g., [5, 9-13]), as compared to other economically important grasses (e.g., [14]).
Important features of similar wetland grasses are the presence of structural and apoplastic barriers, including endodermis, exodermis, and epidermis of roots [9, 15-25], and a sclerenchyma ring (SCR) and peripheral mechanical ring (PMR) in stems and leaves. Metcalfe [5, page 539] even reported a culm endodermis with "suberized walls" in $O$. sativa. The air spaces in the organs include the aerenchyma in roots $[26,27]$ and pith cavities and cortical aerenchyma in stems that transport oxygen for plant survival under submerged stress $[15,17,25]$.

Except for the much studied Oryza, there is limited knowledge of the wetland adaptive structural features in other Ehrhartoideae, specifically, Z. latifolia, that may be important for its use in the restoration of the degraded wetlands in the Jinghan Floodplain and Three Gorges Reservoir Region along the Yangtze River. Thus, we studied the anatomy and histochemistry or roots, stems, and leaves and the permeabilities of apoplastic barriers in emergent Asian wild rice. 


\section{Materials and Methods}

Asian wild rice samples or adult plants were collected in the summer from the Jianghan Floodplain wetland, China. Roots, culms with leaves, stolons, and rhizomes were sectioned fresh or fixed in FAA [28]. Only fresh roots and rhizomes were used for apoplastic permeability tests. We examined sections at $5 \mathrm{~mm}, 10 \mathrm{~mm}, 30 \mathrm{~mm}, 50 \mathrm{~mm}, 70 \mathrm{~mm}$, and $90 \mathrm{~mm}$ from root tips and aged sections of adventitious roots and sections from young and aged sections of the culms, stolons, rhizomes, and leaves. Young stem sections were obtained from the elongated internodes with pith parenchyma. Aged stem sections were taken from internodes with leaf sheaths or scale leaves sloughed off where internodal pith cavities were present.

All roots, stems, and leaves of wild rice samples were sectioned freehand with a two-edged blade technique under a stereoscope. Sections were stained with Sudan red 7B (SR7B) for suberin lamellae [29], berberine hemisulfateaniline blue (BAB) for Casparian bands and lignified cell walls [22, 30], phloroglucinol- $\mathrm{HCl}(\mathrm{Pg})$ for lignin [28], and toluidine blue O (TBO) [22] for cell walls. Specimens were examined under brightfield and epifluorescence microscopy and photographed as described by Yang et al. [25].

Root and rhizome samples were subjected to apoplastic permeability tests. Root samples were excised into $30-40 \mathrm{~mm}$ long segments, blotted dry with tissue paper, and then sealed at the ends with cooling molten sticky wax prior to treatment. The rhizome samples were excised with nodes at each end of an internode, but the ends were not sealed. Sections of five roots and five rhizomes were tested with the apoplastic tracer berberine hemisulfate. Prepared specimens were bathed in $0.05 \%$ berberine hemisulfate for $1 \mathrm{~h}$ followed by $0.05 \mathrm{M}$ potassium thiocyanate for $1 \mathrm{~h}$. Samples were freehand-sectioned and viewed with UV light as described in Meyer et al. [31], Meyer and Peterson [32], and Seago et al. [22]; two controls included unstained sections or were stained only with the tracer.

\section{Results}

The wild rice plants are comprised of rhizomes, stolons, culms, adventitious roots from each of the stems, and leaves of the culms.

3.1. Adventitious Roots. Young or distal regions of wild rice adventitious roots have a stele with differentiating proto- and metaxylem, a cortex with an endodermis, a midcortex with thick cell walls in inner layers, developing schizolysigenous aerenchyma, an enlarged outer ring of cells (not part of the hypodermis), a distinctly biseriate hypodermis, and an epidermis at $5 \mathrm{~mm}$ from the apex (Figure 1(a)). Faint Casparian bands are first visible on the uniseriate exodermis radial walls, and a lignified, very small-celled, inner hypodermal sclerenchyma layer (SC) and protoxylem poles appear at $10 \mathrm{~mm}$ (Figure 1(b)). Endodermis Casparian bands appear and the large-celled exodermis then develops suberin lamellae at $30 \mathrm{~mm}$ from root tips. Both the hypodermal SC layer and the cell layers immediately adjacent to the endodermis stain for lignin and diffuse suberin (Figures $1(\mathrm{c}), 1(\mathrm{~d}), 1(\mathrm{~g})$, and $1(\mathrm{~h})$ ). The endodermal Casparian bands remain faint at $50 \mathrm{~mm}$ from the root apex (Figure 1(e)); the hypodermal SC and exodermis become thick-walled (Figures 1(e), 1(f), and 1(g)) with lignification and additional suberization (Figures $1(\mathrm{~d}), 1(\mathrm{e})$, and $1(\mathrm{~h})$ ). The Casparian bands of the endodermis become prominent and suberin lamellae form at $70 \mathrm{~mm}$ (Figures 1(d), 1(f), and 1(h)); then, secondary wall lignification follows (Figure $1(\mathrm{~g})$ ). When epidermis remains, its small cells have a thin cuticle and appear to contain diffuse suberin (Figure 1(f) and [33]).

In wild rice adventitious roots, schizolysigenous aerenchyma in the middle cortex begins at $5 \mathrm{~mm}$ (Figure 1(a)), and by $50 \mathrm{~mm}$ aerenchyma is lysigenous, characterized by spokes of radial files of cells (Figures 1(f) and $1(\mathrm{~g})$ ). The outermost layer of the midcortex, the layer immediately interior to the SC, has enlarged cells like the exodermis, but its cells are related structurally and developmentally by radial files to the middle and inner cortex. The stele has 8-12 mature protoxylem elements (Figures 1(d), 1(f), and 1(g)) with two to three metaxylem elements (Figures 1(a), 1(d), 1(f), 1(g), and 1(h)), and almost all cells in the stele become lignified as sclerenchyma in aged roots (Figure $1(\mathrm{~g})$ ).

3.2. Stolons, Rhizomes, and Culms with Leaves. Rhizomes, stolons, and culms have two rings of thickened, lignified cells, the peripheral mechanical ring (PMR) and the sclerenchyma ring (SCR); the latter delimits the cortex from the CC (central cylinder) and is usually associated with vascular bundles (Figures 2(a)-2(h)). The outer layer of PMR has suberin lamellae (Figures 2(b), 2(c), 2(e), and 2(g)) without Casparian bands (Figures 2(a) and 2(b)). The cuticle, SCR, PMR, and aerenchyma of culms, stolons, and rhizomes of wild rice are similar. In young culms of wild rice, the cuticle of epidermis is thick (Figure 2(a)); many cells throughout the cortex and central cylinder, vascular bundles, SCR, and PMR show evidence of diffuse suberin (Figure 2(c); [33]). Aged culms (Figure 2(c)) and stolons (Figure 2(e)) also test for diffuse suberin in cells of the SCR, vascular bundles, both layers of cells of PMR (Figures 2(d) and 2(f)), and thick cuticle (Figures 2(b) and 2(c)). There is evidence of lignin in the cuticle (Figure 2(h)). Aged rhizomes have evidence of diffuse suberin in vascular bundles, two layers of cells in the PMR (Figure 2(g)), and lignified vascular bundles and PMR cells (Figure 2(h)).

Air spaces in culms (Figures 2(b) and 2(c)) and stolons (Figures 2(e) and 2(f)) consist of pith cavities and schizolysigeny to lysigenous aerenchyma in the cortex and central cylinder interior to the SCR. Air spaces in rhizomes consist of schizolysigeny to lysigenous aerenchyma in the cortex and pith cavities within the CC (Figures $2(\mathrm{~g})$ and 2(h)).

Leaf sheaths and blades of wild rice have thick cuticles on adaxial and abaxial surfaces (Figures 2(i) and 2(j)), sclerenchyma bundles at both ends of bundle sheath extensions, or ribs and girders, just under epidermis, and schizolysigenous to lysigenous cavities or aerenchyma in leaf sheaths and leaf blades (Figures 2(i) and 2(j)). There is no evidence of 


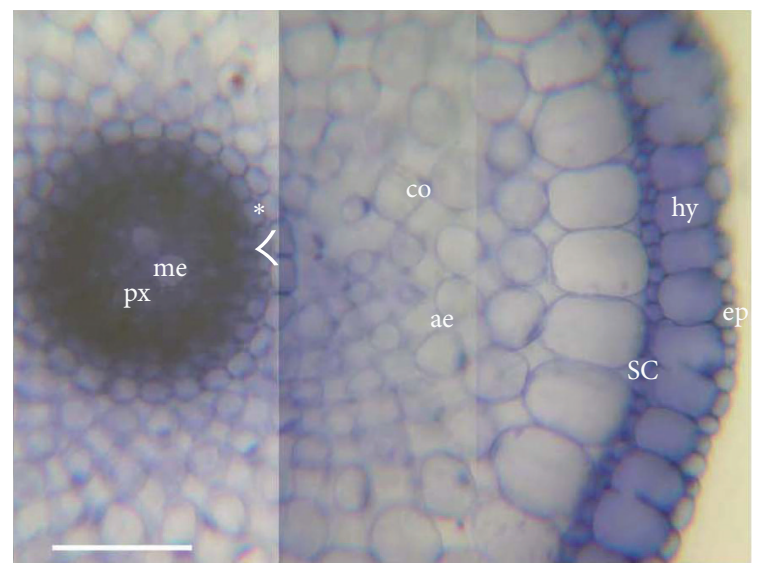

(a)

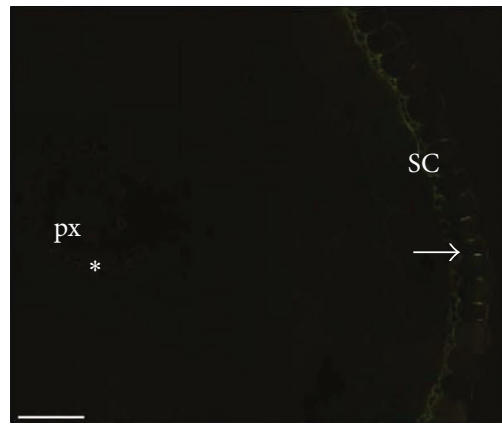

(c)

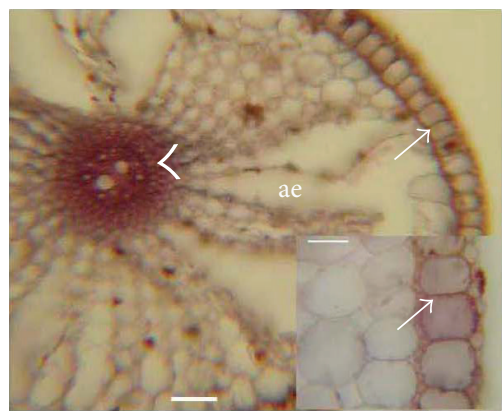

(f)

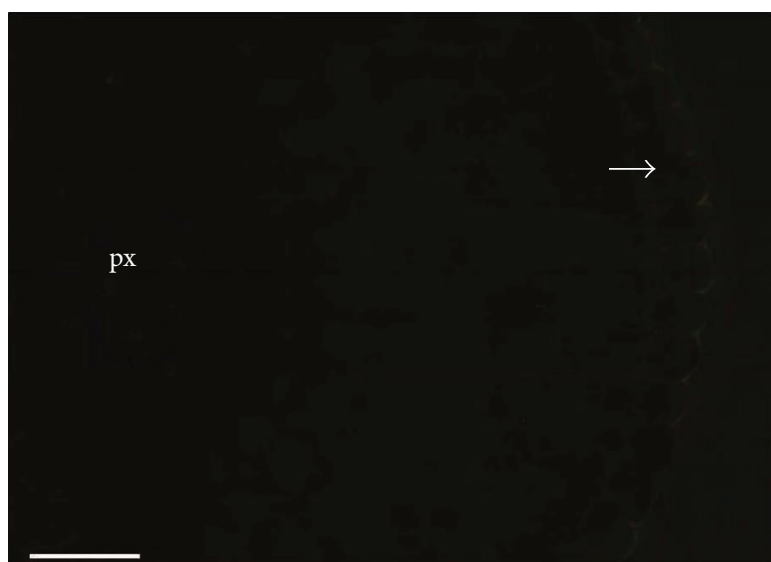

(b)

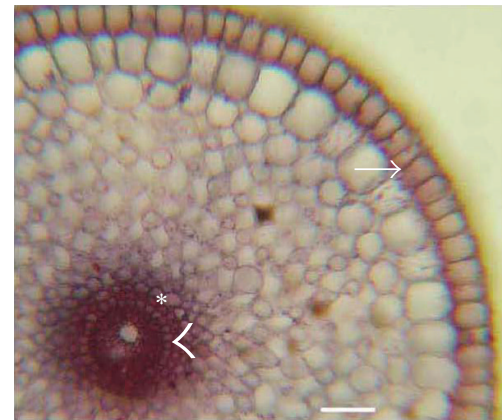

(d)

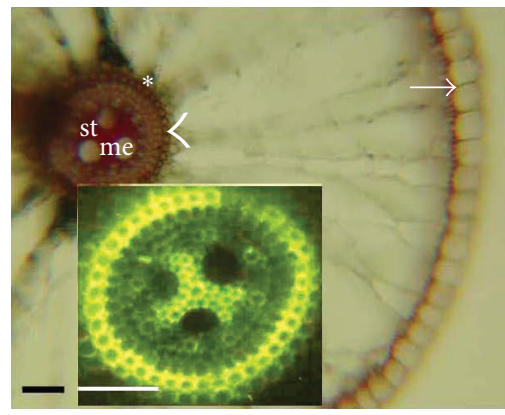

$(\mathrm{g})$

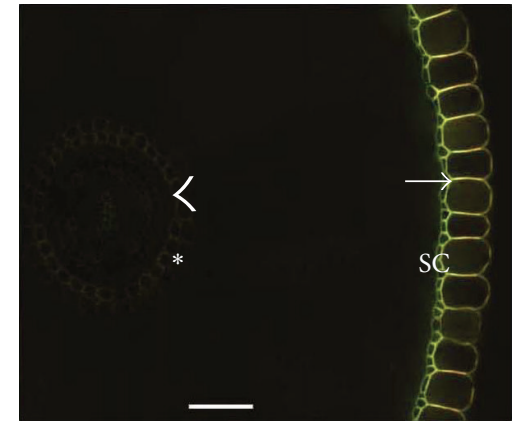

(e)

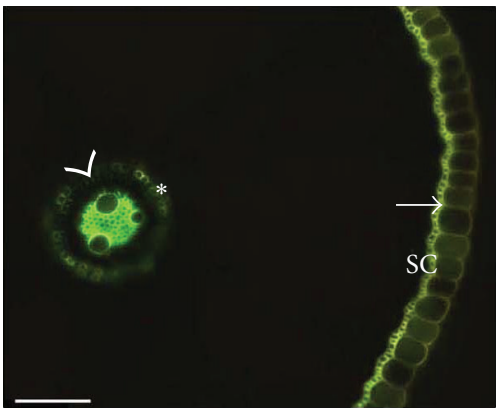

(h)

Figure 1: (a)-(h) Photomicrographs of Zizania latifolia adventitious roots; scale bars $=50 \mu \mathrm{m}$. (a) Root $155 \mathrm{~mm}$ long, sectioned at $5 \mathrm{~mm}$ behind tip; endodermis (arrowheads); adjacent endodermal cortical layers with thickened walls (asterisk); cortex; schizolysigeny aerenchyma; hypodermis; epidermis; sclerenchyma layer; protoxylem; metaxylem; staining: TBO. (b) Root $155 \mathrm{~mm}$ long, sectioned at $10 \mathrm{~mm}$; uniseriate exodermis with weakly Casparian bands (arrows); protoxylem; staining: BAB. (c) Root $155 \mathrm{~mm}$ long at $30 \mathrm{~mm}$; lignified adjacent endodermal cortical layers (asterisk); uniseriate exodermis with Casparian bands (arrows); uniseriate SC; protoxylem; staining: BAB. (d) Root 155 mm long at $30 \mathrm{~mm}$; endodermis suberin lamellae (arrowheads); adjacent endodermal cortical layers suberin lamellae (asterisk); schizolysigeny aerenchyma; suberized SC and exodermis (arrows); staining: SR7B. (e) Root $155 \mathrm{~mm}$ long at $50 \mathrm{~mm}$; endodermis Casparian bands (arrowheads); lignified adjacent endodermal cortical layers (asterisk); uniseriate exodermis Casparian bands (arrows); lignified uniseriate SC; staining: BAB. (f) Root $155 \mathrm{~mm}$ long at $50 \mathrm{~mm}$; endodermis suberin lamellae (arrowheads); schizolysigeny aerenchyma; suberized SC and exodermis (arrows); staining: SR7B. (g) Root $155 \mathrm{~mm}$ long at $50 \mathrm{~mm}$; lignified endodermis (arrowheads); lignified adjacent endodermal cortical layers (asterisk); lignified SC and exodermis (arrows); schizolysigeny aerenchyma; lignified stele pith cells; metaxylem; staining: Pg; inset show protoxylem elements; staining: berberine. (h) Root $155 \mathrm{~mm}$ long at $70 \mathrm{~mm}$; endodermis Casparian bands (arrowheads); lignified adjacent endodermal cortical layers (asterisk); uniseriate exodermis Casparian bands (arrows); lignified uniseriate SC; lignified stele pith cells; staining: BAB. cortex, co; epidermis, ep; hypodermis, hy; metaxylem, me; protoxylem, px; schizolysigenous aerenchyma, ae; sclerenchyma layer, SC; stele, st. 


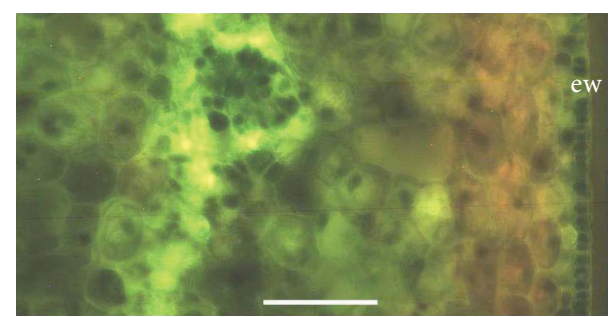

(a)

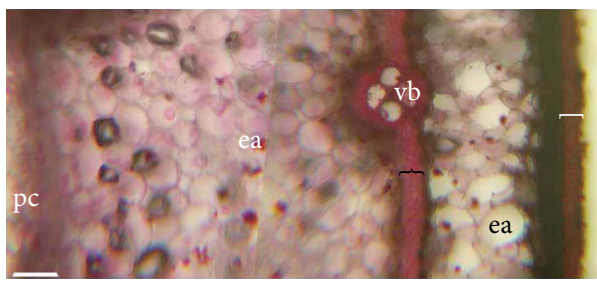

(c)

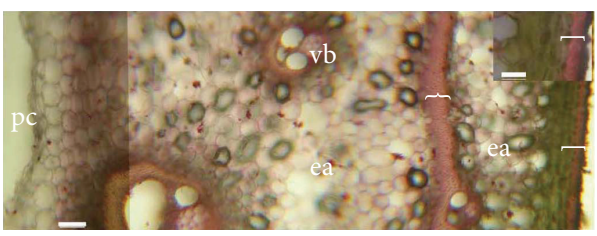

(e)

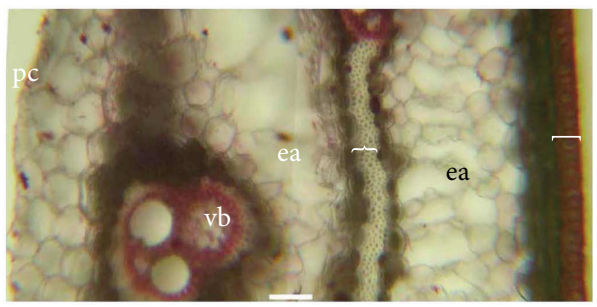

(g)

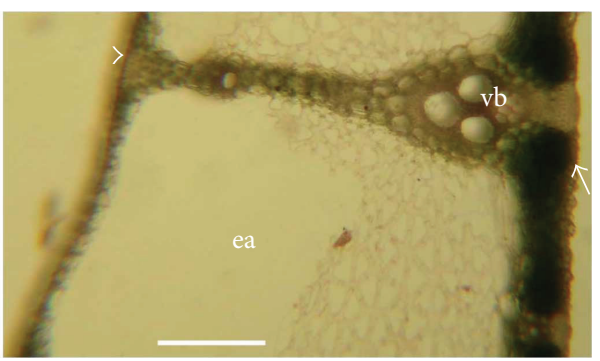

(i)

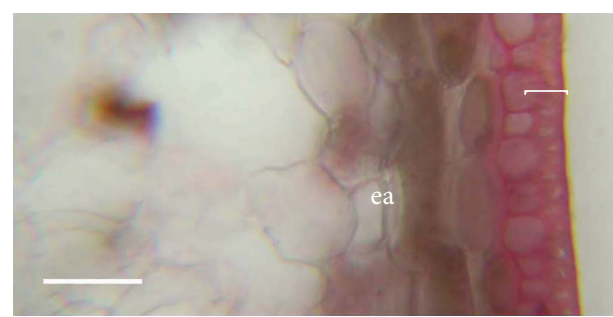

(b)

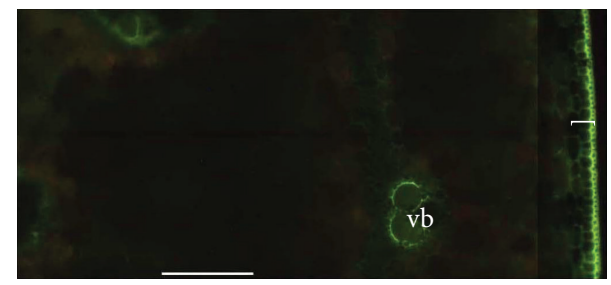

(d)

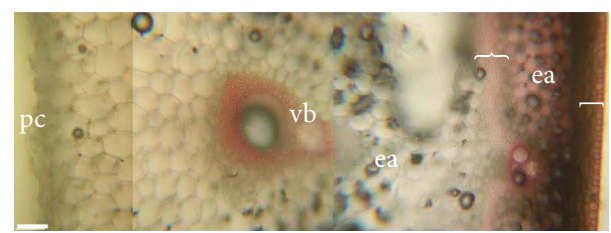

(f)

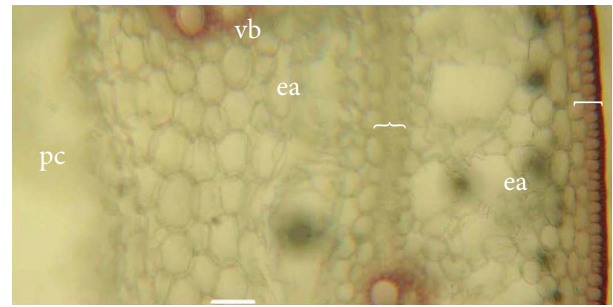

(h)

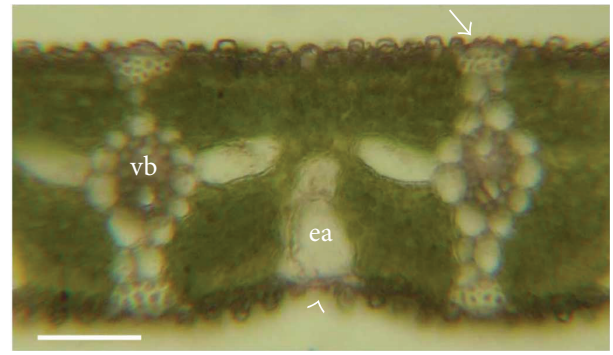

(j)

Figure 2: (a)-(d) Photomicrographs of Zizania latifolia culm (200-280 mm long, 5-8 nodes) sectioned at the first internode (young) and at 3 th internode (aged); (e)-(f) stolons (900 mm long, 8-11 nodes are aged) sectioned at the first internode; (g)-(h) rhizomes (800-910 mm long, 20-24 nodes) sectioned at the 5th internode (aged); (i)-(j) leaf sheath and leaf sectioned; scale bars $=100 \mu \mathrm{m}$. (a). Young culm; epidermis outer tangential walls; staining: BAB. (b) Young culm; outer layer of PMR with suberin lamellae and suberized epidermis (bracket); schizolysigenous aerenchyma; staining: SR7B; bar $=50 \mu \mathrm{m}$. (c) Aged culm; suberized SCR (brace); suberized PMR (bracket); suberized vascular bundle cells; pith cavity; schizolysigeny aerenchyma; staining: SR7B. (d). Aged culm; lignified vascular bundle cells; lignified PMR (bracket); staining: BAB. (e) Aged stolon; SCR (brace); suberized PMR (bracket); suberized vascular bundles; pith cavity; schizolysigeny aerenchyma; staining: SR7B; inset shows suberized PMR (bracket) with suberin lamellae; bar = 50 um. (f) Aged stolon; SCR (brace); lignified vascular bundle cells; lignified PMR (bracket); pith cavity; schizolysigeny aerenchyma; staining: Pg. (g) Aged rhizome; SCR (brace); suberized PMR (bracket); suberized vascular bundle cells; pith cavity; schizolysigeny aerenchyma; staining: SR7B. (h) Aged rhizome; SCR (brace); lignified vascular bundle cells; lignified PMR (bracket); pith cavity; schizolysigeny aerenchyma; staining: Pg. (i) Leaf sheath; cuticle on adaxial surface (arrowhead) and abaxial surface (arrow) of leaf sheath, suberin lamellae on vascular bundle cells; schizolysigeny aerenchyma; staining: SR7B. (j) Leaf blade; cuticle on adaxial surface (arrowhead) and abaxial surface (arrow) of leaf blade; vascular bundle; aerenchyma; staining: SR7B. epidermal cell wall, ew. 
diffuse suberin or suberin lamellae in the sclerenchyma cells of leaves.

\subsection{Permeability Test of Roots and Rhizomes Apoplastic Barri-} ers. The peripheral barrier of wild rice roots is a hypodermis with uniseriate SC and uniseriate exodermis; the barrier of rhizomes is the epidermis with cuticle and PMR with suberin lamellae. Permeability of root and rhizome barriers was tested with a berberine tracer. The stele, endodermis, adjacent cortical layers, and hypodermis in roots, and the epidermis and PMR in rhizomes autofluoresce faintly brown under UV light (Figures 3(a) and 3(b)).

When segments of root and stem were treated directly with berberine hemisulfate, cell walls of the endodermis and hypodermis in roots (Figure 3(c)) and epidermis and PMR in stems fluoresced faintly brown (Figure 3(d)). Berberine thiocyanate crystals adhered to root exodermis outer walls (Figure 3(c)). The hypodermal SC of roots fluoresced yellow (Figure 3(c)).

The cell walls of root endodermis and SC (Figure 3(e)) and of rhizome epidermal cuticle (Figure 3(f)) fluoresced bright orange, when root and stem transverse specimens were stained with berberine and KSCN; no crystals of berberine thiocyanate were observed in the aerenchyma of roots and rhizomes, though sometimes crystals could be found in ruptured root exodermis cells (Figure 3(e)). Yellow crystals of berberine thiocyanate formed in cortical aerenchyma where root exodermis was ruptured (Figure $3(\mathrm{~g})$ ) and in rhizome internodes directly stained by berberine and KSCN (Figure 3(h)). Pith sclerenchyma of roots fluoresced brightly (Figures 3(e) and 3(g)) after staining by berberine and KSCN.

\section{Discussion}

The cortex of wild rice, $Z$. latifolia, adventitious roots is characterized by an endodermis through stage III wall modifications [34] and thick-walled inner cortical cells radially aligned to the endodermis. The midcortex is lysigenous aerenchyma and is bordered by enlarged cells peripherally; the outer cortex is a biseriate hypodermis with uniseriate sclerenchyma layer (SC) and uniseriate exodermis [9], like $Z$. aquatica roots which, however, have a biseriate exodermis [3]. However, there are considerable apparent differences in interpretation of the external barrier layers in species of Zizania. Stover [3,4] showed an early, very small-celled epidermis which sloughs off, but Jorgenson et al. [8] illustrated what they interpreted as epidermis in Z. palustris, although the distance behind the root tip was not provided; it appears to be an old, mature root. It seems that the outermost layer may be uniseriate exodermis underlain by sclerenchyma-uniseriate in some illustrations (drawings) and biseriate in others (photographs in Jorgenson et al. [8]; Tateoka [9] illustrated similar exodermis and sclerenchyma layers, but also included a thin-walled cell layer between the sclerenchyma layer and the enlarged outer mid-cortex layer for Z. latifolia. In the closely related Oryza sativa, a hypodermis is biseriate with an uniseriate, small-celled exodermal layer $[10,13]$ which, like the epidermis, often excises from mature roots [10], leaving the SC as the outer layer of the root. It is not uncommon in Poales, as root tissues complete maturation, for the epidermis to be sloughed off, leaving the exodermis as the outermost layer, or even for both epidermis and exodermis to be sloughed off, leaving the SC as the outermost layer of adventitious roots (e.g., [22, 35]). Such appears to be the situation in Z. palustris; Jorgenson et al. [8] noted that there were no root hairs or epidermal cells on roots, but nevertheless they labeled epidermis cells in their photographs; clearly, an unsubstantiated exodermis is the outermost layer of its mature roots on which iron plaque is found. There are some discrepancies, either in species differences or in interpretations, which may be influenced by the distance behind the root tip for the tissues studied.

The outermost layer of mid-cortex in Z. latifolia is also enlarged but is clearly aligned to the rest of the mid-cortex. Stover $[3,4]$ also illustrated an aerenchyma with schizogenous and lysigenous cortex, but with no enlarged outermost mid-cortex layer, while Jorgenson et al. [8] illustrated such an enlarged layer. In Oryza, the outermost layer of the midcortex is also like that of $Z$. latifolia [13].

Stover's photographs [4] revealed that $Z$. aquatica had 14-16 protoxylem and protophloem poles and 6-8 large metaxylem elements with a parenchymatous pith, and the illustrations in Jorgenson et al. [8] showed 5 metaxylem elements and 12-14 protoxylem elements. We found fewer protoxylem poles (8-12) and metaxylem (2-3) elements in $Z$. latifolia and a sclerenchymatous pith.

With two important exceptions, the stem characteristics of the various Ehrhartoideae are similar; it should be noted that leaf lamina traits have been studied the most [5]. For stems, Metcalfe [5], Esau [34], and Fahn [36] cited Oryza as an example of a grass stem with two rings of vascular bundles, the outer ring of smaller bundles and the inner ring of larger bundles, as we found in Z. latifolia [37, 38]. However, unlike Z. latifolia, and except for Metcalfe's report [5, page 341] that fiber cells, or "peripheral scl." like our PMR, underlie the epidermis, there is no obvious SCR in Oryza [37, 38] or in most other genera of the subfamily [5]; this appears to be a major difference within the Ehrhartoideae. Yet, Metcalfe [5, page 539], who noted a "sclerotic ring" associated with the inner ring of vascular bundles, stated that the culm base had "an endodermis of rounded cells with suberized walls," but we could not detect Casparian bands with our epifluorescence techniques, which were not utilized by Metcalfe [5]. In our study, however, we detected suberin lamellae in the outer layer of PMR in stems, and we observed diffuse suberin in the cells of the well-defined SCR and PMR multicelled rings. The leaves of $Z$. latifolia have the structural features dominated by the large air spaces and the nonsuberized sclerenchyma extensions of veins, termed ribs and girders by Metcalfe [5].

Roots and stems of wild rice, $Z$. latifolia, are also similar to those of other grasses we have studied [25], except that the sclerenchyma rings in Z. latifolia are narrower than in Cynodon dactylon and Paspalum distichum, for example. With regard to barrier layers, wild rice endodermis is typical of grass roots, for example, $[14,25]$. The root hypodermis seems superficially similar to Glyceria maxima [24], but the exodermisof Glyceria maxima has thickened secondary cell 


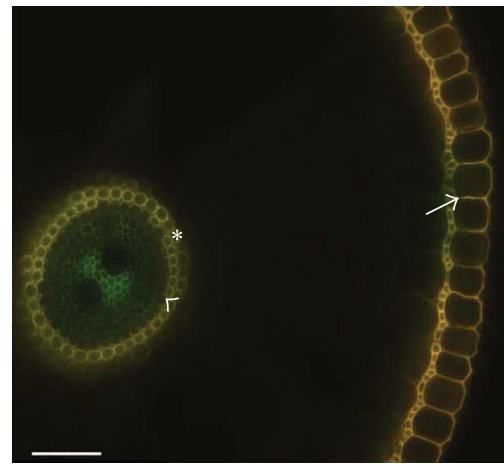

(a)

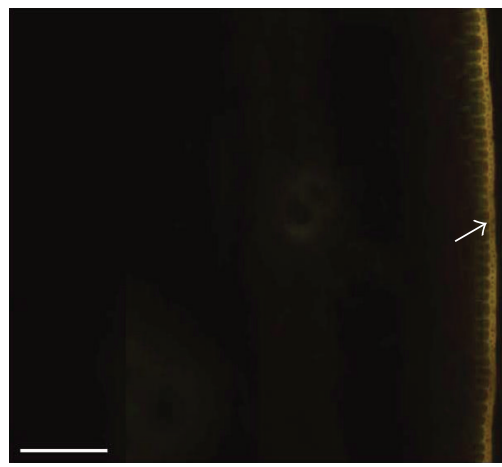

(d)

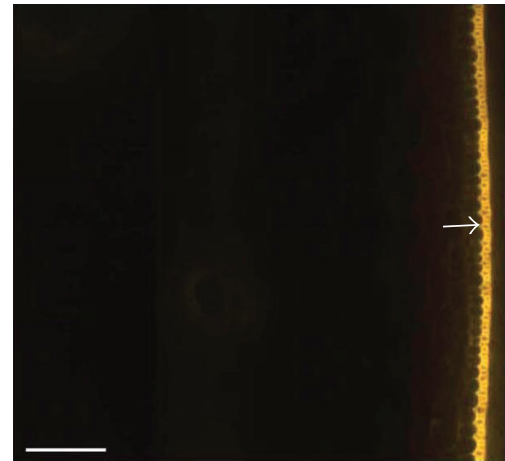

(b)

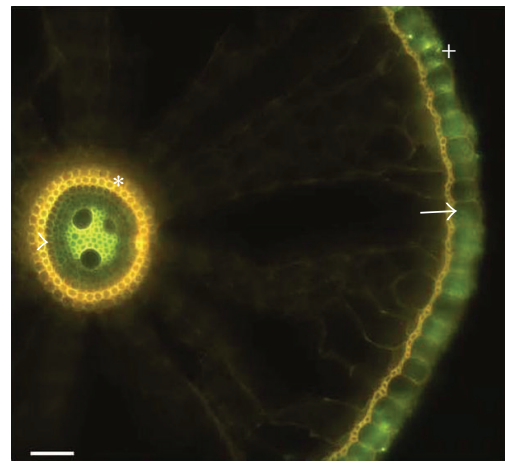

(e)

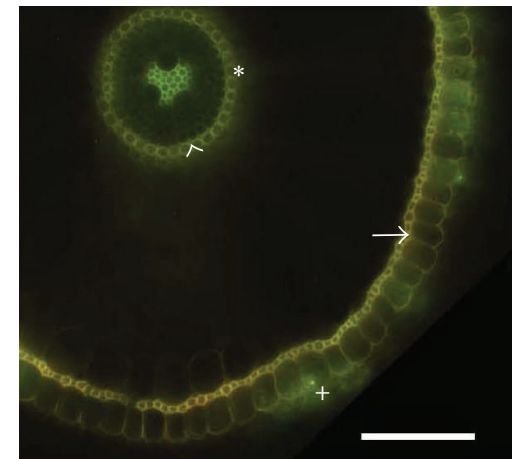

(c)

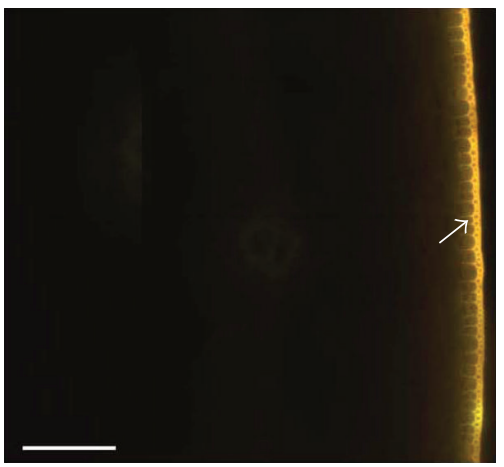

(f)

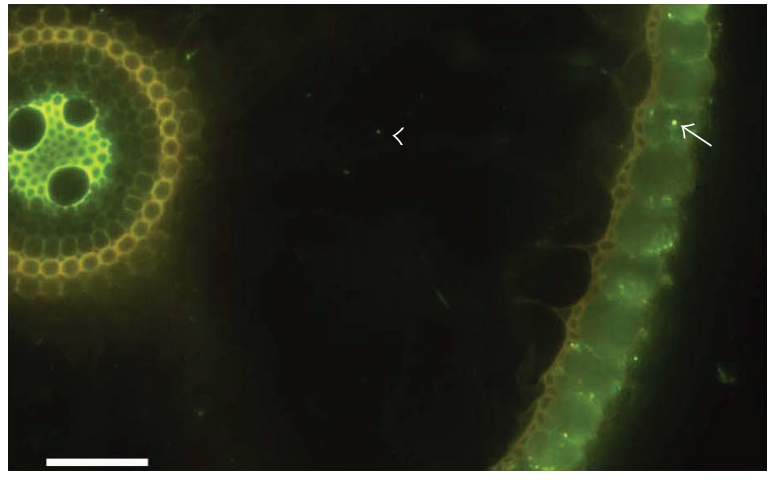

(g)

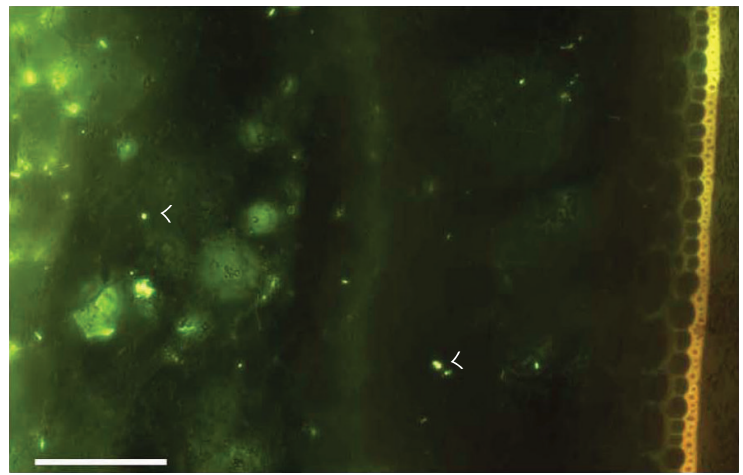

(h)

FIGURE 3: Apoplastic barriers permeability tests on roots and rhizomes collected from grow in wetland with berberine tracer. Roots segments sectioned at $30 \mathrm{~mm}$ to $60 \mathrm{~mm}$ from the tip of $130 \mathrm{~mm}$ long roots and sealed ends. The aged rhizome (as stem representative for culms and stolons have similar structure and histochemistry) samples excised with one internode and two end nodes and not sealed ends; except where noted, scale bars $=100 \mu \mathrm{m}$. (a) Roots with aerenchyma; thickened adjacent endodermal cortical layers (asterisk), endodermis (arrowhead) and exodermis (arrow) cell walls faintly brown; unstained; bar $=50 \mu \mathrm{m}$. (b) The epidermis and PMR of rhizomes faintly brown (arrow); unstained. (c) Roots with aerenchyma; thickened adjacent endodermal cortical layers (asterisk), endodermis (arrowhead) and exodermis cell walls (arrow) fluoresced yellow; crystals of berberine thiocyanate (cross) enter into exodermis or out of it; berberine stained; bar $=50 \mu \mathrm{m}$. (d). The epidermis and PMR of rhizomes fluoresced yellow (arrow); berberine stained. (e) Roots with aerenchyma; thickened adjacent endodermal cortical layers (asterisk), endodermis (arrowhead), and exodermis cell walls (arrow) fluoresced yellow; crystals of berberine thiocyanate (cross) enter into exodermis or out of it; berberine and KSCN stained. (f) The epidermis and PMR of rhizomes fluoresced yellow (arrow); berberine and KSCN stained. (g) Roots with ruptured exodermis; crystals of berberine thiocyanate enter into aerenchyma (arrowhead) and exodermis (arrow); berberine and KSCN stained; bar $=50 \mu \mathrm{m}$. (h) The transverse sections of rhizomes internodes; crystals of berberine thiocyanate (arrowhead) adhere to aerenchyma and pith cavity; berberine and KSCN stained. 
walls without a sclerenchyma layer. Air space tissues in wild rice roots have mostly radial lysigeny [26], typical of many other wetland species (e.g., $[26,27,39,40]$ ).

Wild rice stems have lignified PMR, with unique suberin lamellae and diffuse suberin that is somewhat unlike Cynodon dactylon, Paspalum distichum, and Hemarthria altissima; grasses can have suberin lamellae in their stems [36] and leaves (e.g., [41]), and an inner hypodermal layer with suberin lamellae was found in Pontederia cordata roots [42]. Wild rice stems also have lignified vascular bundle cells, again with some evidence of suberin, but they are only lignified in Cynodon dactylon, Eremochloa ophiuroides, Paspalum distichum, and Hemarthria altissima. Wild rice culms and stolons have SCR with lignin and apparent suberin, but in C. dactylon, E. ophiuroides, Paspalum distichum, and H. altissima the SCR is only lignified [25] and in other grasses like Glyceria maxima, there is a SCR connecting the inner ring of vascular bundles [5], unlike the other members of the Ehrhartoideae. Wild rice stems are unlike Typha because they have no exodermis and endodermis with Casparian bands [43]. A thickened cuticle is also present in wild rice epidermis as well as in Typha, Cynodon dactylon, and other stoloniferous grasses that we have been studied $[25,43]$, but diffuse suberin in epidermal cell walls appears to be unusual [33].

Schizo-lysigeny to lysigenous aerenchyma in wild rice stem and leaf cortex is normal and makes wild rice similar to Cynodon dactylon, Eremochloa ophiuroides, Hemarthria altissima, and Miscanthus sacchariflorus [25-27, 40]. These constitutively formed air spaces [12] obviously store and transport oxygen to organs in hypoxic environments $[15,17$, $39,44]$.

Finally, the impermeable barriers in roots and stems in wild rice are manifested by the blockage of berberine tracers in root endodermis/exodermis and stem PMR. These barriers allow the adaptability of these plants to wetland environments, as is typical of other wetland plants like $C$. dactylon, E. ophiuroides, $H$. altissima, Phragmites australis, Paspalum distichum, and Typha [16, 22-25, 31, 43, 45-48]. The apoplastic barriers in wild rice plant would efficiently hinder oxygen and solute exchange under water stress (e.g., [32, 4954]). The deposition of suberin and lignin wall materials and the early maturation of exodermis in wild rice roots have also been reported variously in many species (e.g., $[13,22-$ $26,52])$.

In conclusion, the structures and histochemistry of these perennial and rhizomatous grasses enhance our understanding of the biological features of the Ehrhartoideae of the Poaceae and other wetland species adapted to aquatic habitats and provide clues to the selection of plants useful in the restoration of the degraded Jianghan Floodplain and riparian zone of the Three Gorges Reservoir Region of the Yangtze River.

\section{Conflict of Interests}

The authors declare that there is no conflict of interests regarding to the publication of this paper.

\section{Acknowledgment}

This work was supported by a Grant from Special Fund for Agro-scientific Research in the Public Interest, China (Grant no. 201303031).

\section{References}

[1] E. J. Judziewicz and L. G. Clark, "Classification and biogeography of New World grasses: Anomochlooideae, Pharoideae, Ehrhartoideae, and Bambusoideae," in Monocots: Comparative Biology and Evolution Poales, J. T. Columbus, E. A. Friar, J. M. Porter, L. M. Prince, and M. G. Simpson, Eds., pp. 303314, Rancho Santa Ana Botanic Garden, Claremont, Calif, USA, 2007.

[2] C. D. Sculthorpe, The Biology of Aquatic Vascular Plants, Edward Arnold, London, UK, 1967.

[3] E. L. Stover, “The roots of wild rice. Zizania aquatica L.," Ohio Journal of Science, vol. 23, pp. 43-49, 1928.

[4] E. L. Stover, An Introduction to the anatomy of Seed Plants, D. C. Heath and Company, Boston, Mass, USA, 1951.

[5] C. R. Metcalfe, Anatomy of the Monocotyledons. I. Gramineae, Oxford University Press, London, UK, 1960.

[6] C. C. Hsieh, "The vegetative body anatomy of Zizania caduciflora," Journal of Huazhong Agricultural College, vol. 3, pp. 7077, 1984.

[7] H. Yang, X. Li, D. Yu, G. Liu, and L. Luo, "Anatomical characteristics of C4 and C3 photosynthetic-pathway Poaceae plants in Hainan," Chinese Bulletin of Botany, vol. 46, no. 4, pp. 456-469, 2011.

[8] K. D. Jorgenson, P. F. Lee, and K. Kanavillil, "Ecological relationships of wild rice, Zizania spp. 11. Electron microscopy study of iron plaques on the roots of northern wild rice (Zizania palustris)," Botany, vol. 91, no. 3, pp. 189-201, 2013.

[9] T. Tateoka, "Root anatomy in grass systematics," Bulletin of the National Science Museum, Tokyo, vol. 12, pp. 643-651, 1969.

[10] L. H. Clark and W. H. Harris, "Observations on the anatomy of rice (Oryza sativa L.)," American Journal of Botany, vol. 68, no. 2, pp. 154-161, 1981.

[11] T. D. Colmer, "Aerenchyma and an inducible barrier to radial oxygen loss facilitate root aeration in upland, paddy and deepwater rice (Oryza sativa L.)," Annals of Botany, vol. 91, pp. 301309, 2003.

[12] M. Kawai, P. K. Samarajeewa, R. A. Barrero, M. Nishiguchi, and H. Uchimiya, "Cellular dissection of the degradation pattern of cortical cell death during aerenchyma formation of rice roots," Planta, vol. 204, no. 3, pp. 277-287, 1998.

[13] L. Kotula, K. Ranathunge, L. Schreiber, and E. Steudle, "Functional and chemical comparison of apoplastic barriers to radial oxygen loss in roots of rice (Oryza sativa L.) grown in aerated or deoxygenated solution," Journal of Experimental Botany, vol. 60, no. 7, pp. 2155-2167, 2009.

[14] O. T. Bonnett, “The oat plant: its histology and development," Illinois Agricultural Experiment Station Bulletin, vol. 672, pp. 1112, 1961.

[15] J. Armstrong, R. E. Jones, and W. Armstrong, "Rhizome phyllosphere oxygenation in Phragmites and other species in relation to redox potential, convective gas flow, submergence and aeration pathways," New Phytologist, vol. 172, no. 4, pp. 719731, 2006. 
[16] W. Armstrong, D. Cousins, J. Armstrong, D. W. Turner, and P. M. Beckett, "Oxygen distribution in wetland plant roots and permeability barriers to gas-exchange with the rhizosphere: a microelectrode and modelling study with Phragmites australis," Annals of Botany, vol. 86, no. 3, pp. 687-703, 2000.

[17] T. D. Colmer, "Long-distance transport of gases in plants: a perspective on internal aeration and radial oxygen loss from roots," Plant, Cell and Environment, vol. 26, no. 1, pp. 17-36, 2003.

[18] L. Kotula and E. Steudle, "Measurements of oxygen permeability coefficients of rice (Oryza sativa L.) roots using a new perfusion technique," Journal of Experimental Botany, vol. 60, no. 2, pp. 567-580, 2009.

[19] L. Kotula, K. Ranathunge, and E. Steudle, "Apoplastic barriers effectively block oxygen permeability across outer cell layers of rice roots under deoxygenated conditions: roles of apoplastic pores and of respiration," New Phytologist, vol. 184, no. 4, pp. 909-917, 2009.

[20] K. Ranathunge, J. Lin, E. Steudle, and L. Schreiber, "Stagnant deoxygenated growth enhances root suberization and lignifications, but differentially affects water and $\mathrm{NaCl}$ permeabilities in rice (Oryza sativa L.) roots," Plant, Cell and Environment, vol. 34, no. 8, pp. 1223-1240, 2011.

[21] L. Schreiber, R. Franke, K. Hartmann, K. Ranathunge, and E. Steudle, "The chemical composition of suberin in apoplastic barriers affects radial hydraulic conductivity differently in the roots of rice (Oryza sativa L. cv. IR64) and corn (Zea mays L. cv. Helix)," Journal of Experimental Botany, vol. 56, no. 415, pp. 1427-1436, 2005.

[22] J. L. Seago Jr., C. A. Peterson, D. E. Enstone, and C. A. Scholey, "Development of the endodermis and hypodermis of Typha glauca Godr. and Typha angustifolia L. roots," Canadian Journal of Botany, vol. 77, no. 1, pp. 122-134, 1999.

[23] A. Soukup, O. Votrubová, and H. Čížková, "Development of anatomical structure of roots of Phragmites australis," New Phytologist, vol. 153, no. 2, pp. 277-287, 2002.

[24] A. Soukup, W. Armstrong, L. Schreiber, R. Franke, and O. Votrubová, "Apoplastic barriers to radial oxygen loss and solute penetration: a chemical and functional comparison of the exodermis of two wetland species, Phragmites australis and Glyceria maxima," New Phytologist, vol. 173, no. 2, pp. 264-278, 2007.

[25] C. D. Yang, X. Zhang, C. Y. Zhou, and J. L. Seago Jr., "Root and stem anatomy and histochemistry of four grasses from the Jianghan Floodplain along the Yangtze River, China," Flora, vol. 206, no. 7, pp. 653-661, 2011.

[26] J. L. Seago Jr., L. C. Marsh, K. J. Stevens, A. Soukup, O. Votrubová, and D. E. Enstone, "A re-examination of the root cortex in wetland flowering plants with respect to aerenchyma," Annals of Botany, vol. 96, no. 4, pp. 565-579, 2005.

[27] J. Jung, S. C. Lee, and H. Choi, "Anatomical patterns of aerenchyma in aquatic and wetland plants," Journal of Plant Biology, vol. 51, no. 6, pp. 428-439, 2008.

[28] W. A. Jensen, Botanical Histochemistry-Principles and Practice, W. H. Freeman, San Francisco, Calif, USA, 1962.

[29] M. C. Brundrett, B. Kendrick, and C. A. Peterson, "Efficient lipid staining in plant material with Sudan Red 7B or fluoral yellow 088 in polyethylene glycol-glycerol," Biotechnic and Histochemistry, vol. 66, no. 3, pp. 111-116, 1991.

[30] M. C. Brundrett, D. E. Enstone, and C. A. Peterson, "A berberine-aniline blue fluorescent staining procedure for suberin, lignin, and callose in plant tissue," Protoplasma, vol. 146, no. 2-3, pp. 133-142, 1988.

[31] C. J. Meyer, J. L. Seago Jr., and C. A. Peterson, "Environmental effects on the maturation of the endodermis and multiseriate exodermis of Iris germanica roots," Annals of Botany, vol. 103, no. 5, pp. 687-702, 2009.

[32] C. J. Meyer and C. A. Peterson, "Casparian bands occur in the periderm of Pelargonium hortorum stem and root," Annals of Botany, vol. 107, no. 4, pp. 591-598, 2011.

[33] L. Schreiber and R. B. Franke, "Endodermis and exodermis in roots," in ELS, John Wiley \& Sons, Chichester, UK, 2011.

[34] K. Esau, Plant Anatomy, John Wiley \& Sons, New York, NY, USA, 1965.

[35] E. Hose, D. T. Clarkson, E. Steudle, L. Schreiber, and W. Hartung, "The exodermis: a variable apoplastic barrier," Journal of Experimental Botany, vol. 52, no. 365, pp. 2245-2264, 2001.

[36] A. Fahn, Plant Anatomy, Pergamon Press, Oxford, UK, 1990.

[37] L. Jin, Q. Z. Xue, J. F. Xiao, and X. Y. Zhang, "Comparative studies on stem anatomical structure of rice plants with various ploidy level," Journal of Zhejiang University, vol. 35, no. 5, pp. 489-496, 2009.

[38] Y. H. Yang, Z. Zhu, Y. D. Zhang, Q. Y. Zhao, L. H. Zhou, and C. L. Wang, "Relationship between anatomic structure of the stem and lodging resistance of rice," Guihaia, vol. 32, pp. 834-839, 2012.

[39] S. H. F. W. Justin and W. Armstrong, "The anatomical characteristics of roots and plant response to soil flooding," New Phytologist, vol. 106, no. 3, pp. 465-495, 1987.

[40] A. G. Sangster, "Silicon distribution and anatomy of the grass rhizome, with special reference to Miscanthus sacchariflorus (Maxim.) Hackel," Annals of Botany, vol. 55, no. 5, pp. 621-634, 1985.

[41] R. F. Evert, W. A. Russin, and A. M. Bosabalidis, "Anatomical and ultrastructural changes associated with sink-to-source transition in developing maize leaves," International Journal of Plant Sciences, vol. 157, no. 3, pp. 247-261, 1996.

[42] J. L. Seago Jr., C. A. Peterson, and D. E. Enstone, "Cortical development in roots of the aquatic plant Pontederia cordata (Pontederiaceae)," American Journal of Botany, vol. 87, no. 8, pp. 1116-1127, 2000.

[43] H. A. McManus, J. L. Seago Jr., and L. C. Marsh, "Epifluorescent and histochemical aspects of shoot anatomy of Typha latifolia L., Typha angustifolia L. and Typha glauca Godr.", Annals of Botany, vol. 90, no. 4, pp. 489-493, 2002.

[44] B. B. Vartapetian and M. B. Jackson, "Plant adaptations to anaerobic stress," Annals of Botany A, vol. 79, pp. 3-20, 1997.

[45] L. M. Ma, Y. P. Tang, M. Zhang, T. Yan-Hang, L. Dong-Yan, and $\mathrm{Z}$. Jian-Fu, "Evaluation of adaptability of plants in waterfluctuation-zone of the threeg gorges reservoir," Acta Ecologica Sinica, vol. 29, no. 4, pp. 1885-1892, 2009.

[46] S. D. Tan, S. J. Zhang, K. R. Zhang, H. S. Dang, M. Li, and Q. F. Zhang, "Effect of long-time and deep submergence on recovery growth and photosynthesis of three grass species in Three Gorges Reservoir Area," Journal of Wuhan Botanical Research, vol. 27, no. 4, pp. 391-396, 2009.

[47] S. D. Tan, M. Y. Zhu, H. S. Dang, Y. Wang, and Q. Zhang, "Physiological responses of Bermudagrass (Cynodon dactylon (L. ) Pers. ) to deep submergence stress in the Three Gorges Reservoir Area," Acta Ecologica Sinica, vol. 29, no. 7, pp. 36853692, 2009. 
[48] H. Wang, B. Zeng, Y. Li, P. Qiao, X. Ye, and F. Luo, "Effects of long-term submergence on survival and recovery growth of four riparian plant species in Three Gorges Reservoir region," China Journal of Plant Ecology, vol. 32, no. 5, pp. 977-984, 2008.

[49] K. Ranathunge, E. Steudle, and R. Lafitte, "Control of water uptake by rice (Oryza sativa L.): role of the outer part of the root," Planta, vol. 217, no. 2, pp. 193-205, 2003.

[50] J. Armstrong, F. Afreen-Zobayed, S. Blyth, and W. Armstrong, "Phragmites australis: effects of shoot submergence on seedling growth and survival and radial oxygen loss from roots," Aquatic Botany, vol. 64, no. 3-4, pp. 275-289, 1999.

[51] T. D. Colmer, M. R. Gibberd, A. Wiengweera, and T. K. Tinh, "The barrier to radial oxygen loss from roots of rice (Oryza sativa L.) is induced by growth in stagnant solution," Journal of Experimental Botany, vol. 49, no. 325, pp. 1431-1436, 1998.

[52] D. E. Enstone, C. A. Peterson, and F. Ma, "Root endodermis and exodermis: structure, function, and responses to the environment," Journal of Plant Growth Regulation, vol. 21, no. 4, pp. 335-351, 2002.

[53] P. Krishnamurthy, K. Ranathunge, R. Franke, H. S. Prakash, L. Schreiber, and M. K. Mathew, "The role of root apoplastic transport barriers in salt tolerance of rice (Oryza sativa L.)," Planta, vol. 230, no. 1, pp. 119-134, 2009.

[54] P. Krishnamurthy, K. Ranathunge, S. Nayak, L. Schreiber, and M. K. Mathew, "Root apoplastic barriers block $\mathrm{Na}+$ transport to shoots in rice (Oryza sativa L.)," Journal of Experimental Botany, vol. 62, no. 12, pp. 4215-4228, 2011. 

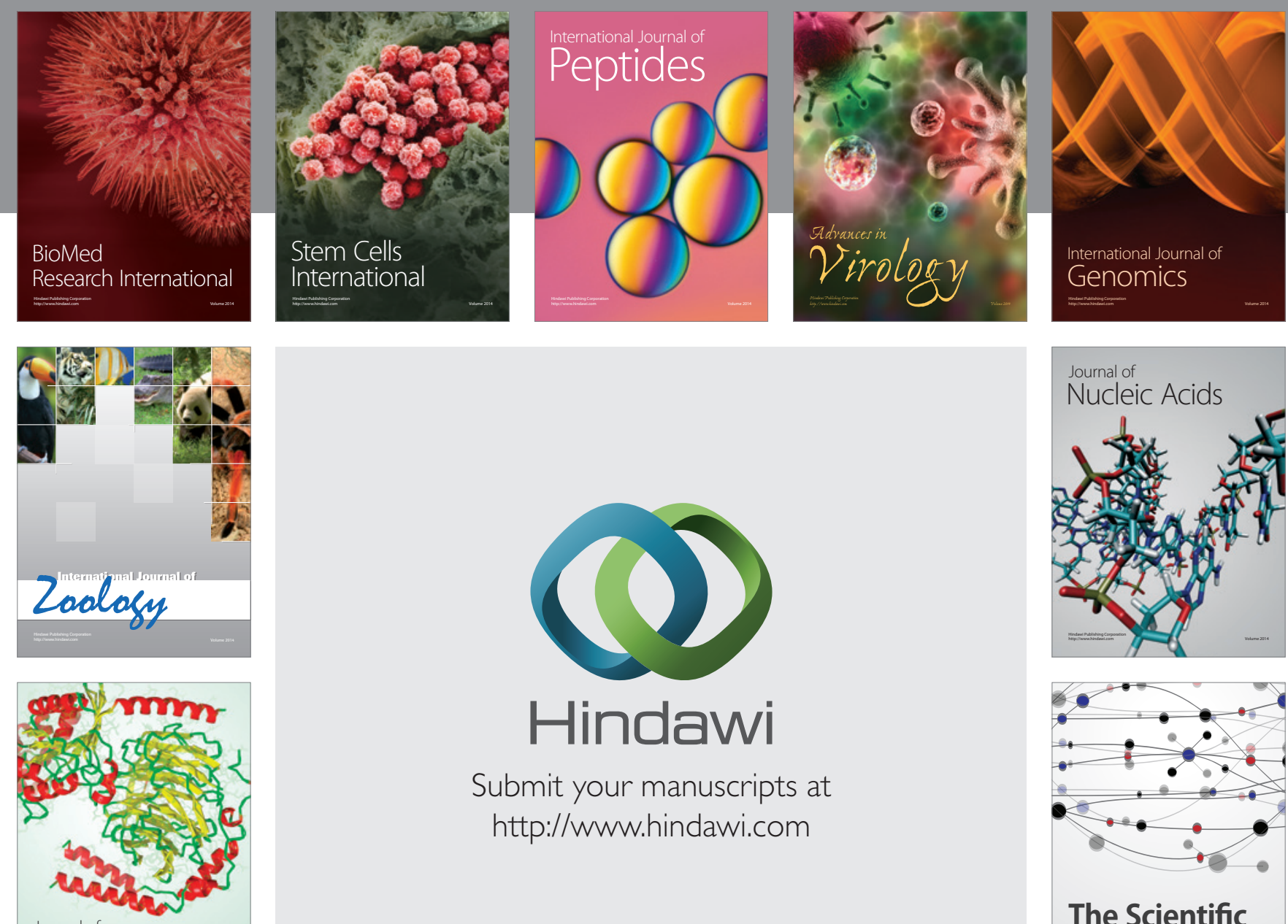

Submit your manuscripts at

http://www.hindawi.com

Journal of
Signal Transduction
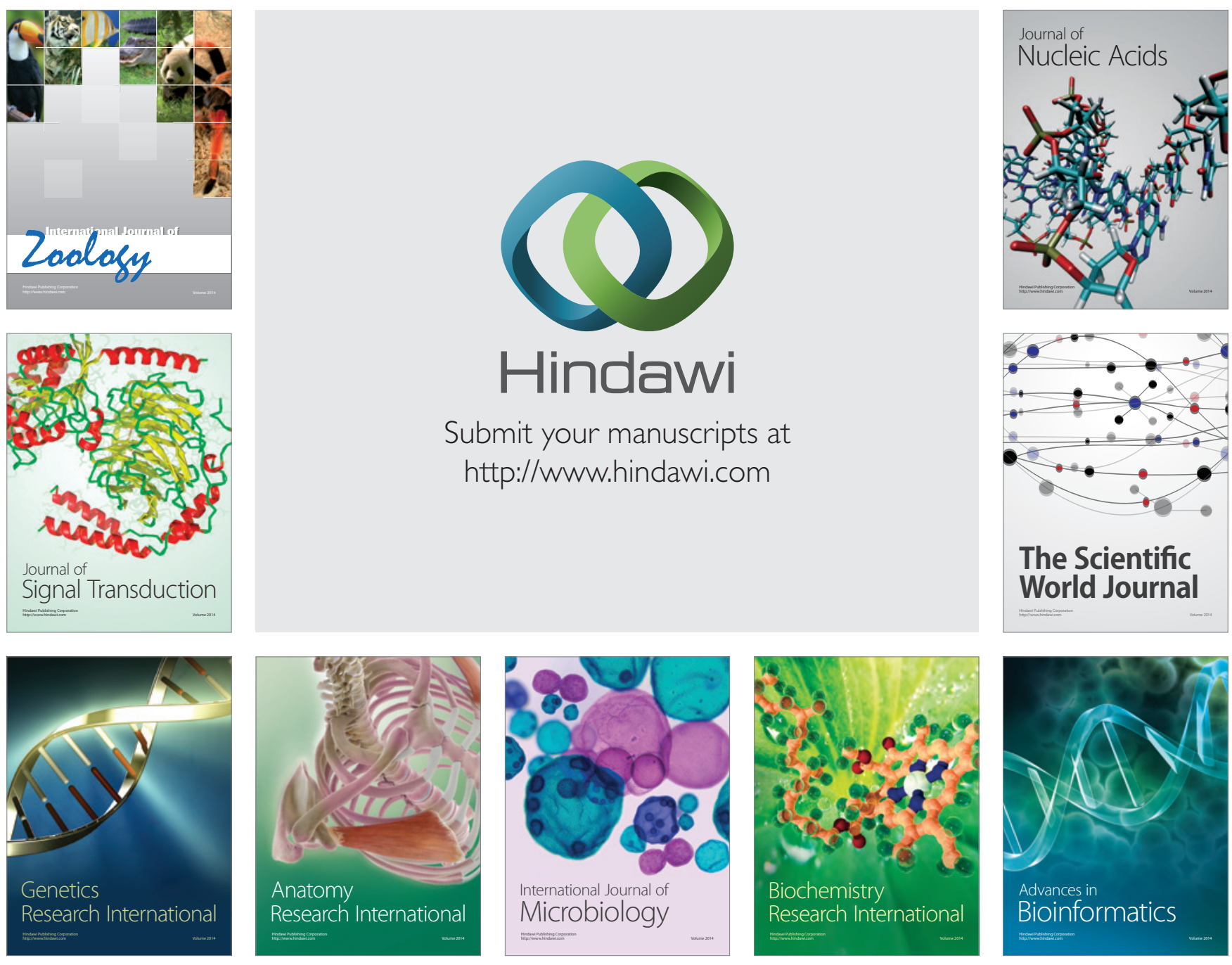

The Scientific World Journal
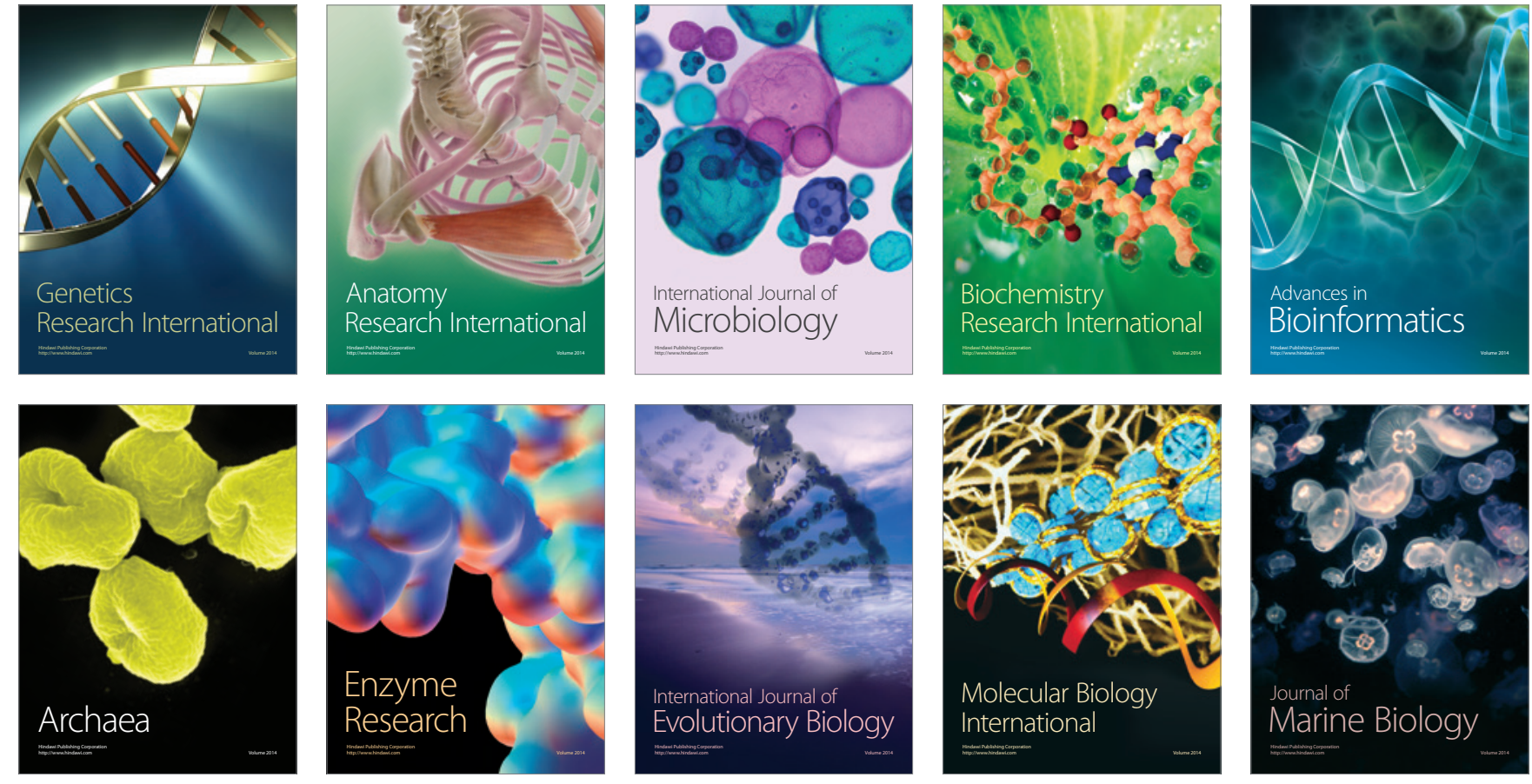